\title{
Conversion of glucose to lactic acid derivatives with mesoporous Sn-MCM-41 and microporous titanosilicates
}

\begin{tabular}{|r|l|}
\hline Journal: & Journal of Chemical Technology \& Biotechnology \\
\hline Manuscript ID: & Draft \\
\hline Wiley - Manuscript type: & Research Article \\
\hline Complete List of Authors: & $\begin{array}{l}\text { Murillo, Beatriz; Universidad de Zaragoza, Department of Chemical and } \\
\text { Environmental Engineering and Institute of Nanoscience of Aragon } \\
\text { Sánchez, Arantxa; Universidad de Zaragoza, Department of Chemical and } \\
\text { Environmental Engineering and Institute of Nanoscience of Aragon } \\
\text { Sebastián, Víctor; Universidad de Zaragoza, Department of Chemical and } \\
\text { Environmental Engineering and Institute of Nanoscience of Aragon } \\
\text { Casado, Clara; Universidad de Cantabria, Department of Chemical } \\
\text { Engineering and Inorganic Chemistry } \\
\text { de la Iglesia, Oscar; Universidad de Zaragoza, Department of Chemical and } \\
\text { Environmental Engineering and Institute of Nanoscience of Aragon } \\
\text { López-Ram-de-Viu, Maria Pilar; Universidad de Zaragoza, Department of } \\
\text { Organic Chemistry and Instituto de Síntesis Química y Homogénea } \\
\text { Tellez, Carlos; Universidad de Zaragoza, Department of Chemical and } \\
\text { Environmental Engineering and Institute of Nanoscience of Aragon } \\
\text { Coronas, Joaquín; Universidad de Zaragoza, Department of Chemical and } \\
\text { Environmental Engineering and Institute of Nanoscience of Aragon }\end{array}$ \\
\hline Key Words: & $\begin{array}{l}\text { Biomass, Heterogeneous Catalysis, Catalytic Processes, Industrial } \\
\text { biotechnology, Sustainable Processing, Zeolites }\end{array}$ \\
\hline \multicolumn{2}{|l}{} \\
\hline \multirow{2}{*}{}
\end{tabular}


1 Conversion of glucose to lactic acid derivatives with mesoporous Sn-

\section{MCM-41 and microporous titanosilicates}

3

4 Short title: Glucose to lactic acid with different catalysts

5

6 Beatriz Murillo ${ }^{1}$, Arantxa Sánchez ${ }^{1}$, Víctor Sebastián ${ }^{1}$, Clara Casado $^{2}$, Oscar de la 7 Iglesia ${ }^{1}$, María P. López-Ram-de-Viu ${ }^{3}$, Carlos Téllez ${ }^{1}$, Joaquín Coronas ${ }^{1}$

8

$9 \quad{ }^{1}$ Department of Chemical and Environmental Engineering and Instituto de Nanociencia 10 de Aragón (INA), Universidad de Zaragoza, 50018 Zaragoza. Spain

$11{ }^{2}$ Department of Chemical Engineering and Inorganic Chemistry, Universidad de 12 Cantabria, 39005 Santander, Spain

$13{ }^{3}$ Department of Organic Chemistry and Instituto de Síntesis Química y Homogénea 14 (ISQCH), Universidad de Zaragoza-CSIC, 50009 Zaragoza. Spain

*Corresponding author:

Dr. Carlos Téllez de Aragón (INA), Universidad de Zaragoza

50018 Zaragoza, Spain

e-mail: ctellez@unizar.es. 


\section{Abstract}

2 Background: The production of value-added products from biomass has acquired 3 increasing importance due to the high worldwide demand for chemicals and energy, 4 uncertain petroleum availability and the necessity of finding environmentally friendly 5 processes. In this work we present the synthesis of several catalysts for the conversion 6 of glucose to methyl lactate.

7 Results: A MCM-41 type mesoporous material containing tin $(\mathrm{Si} / \mathrm{Sn}=55)$ was 8 developed with a uniform ordered mesoporous structure, high specific surface area and 9 high pore volume. Sn-MCM-41 was tested in three consecutive catalytic cycles to 10 evaluate its reusability giving methyl lactate yields of $43 \%, 41 \%$ and $39 \%$, in each 11 cycle. The slightly reduction in activity could be explained by the reduction in the 12 accessibility of active centers due to the adsorption of reaction products and structural 13 changes. Microporous titanosilicates and MFI-type zeolite ZSM-5 showed a lower 14 catalytic performance, but exfoliated materials give higher yields to methyl lactate and 15 pyruvaldehyde dimethyl acetal than their respective layered precursors.

16 Conclusions: Sn-MCM-41 material showed good results in the conversion of glucose to 17 methyl lactate even in three catalytic cycles and exfoliated materials facilitated the 18 access of glucose to the catalytic sites and fast desorption of products.

21 Keywords: Glucose conversion; Lactic acid; Sn-MCM-41; Porous titanosilicates; 22 exfoliated materials 


\section{Introduction}

2 Nowadays, there is a growing interest in developing alternatives for replacing fossil 3 sources due to unknown petroleum availability, high worldwide demand for chemicals 4 and energy and concern about climate change. Besides, there is a need to develop 5 methods to decrease global greenhouse gas emissions by consuming feedstock produced 6 by plant growth photosynthesis, neutral in terms of $\mathrm{CO}_{2}$ balance. ${ }^{1}$ In fact, at the

7 beginning of the $20^{\text {th }}$ century, many industrial materials such as dyes, solvents and 8 synthetic fibers were made from trees and agricultural crops ${ }^{2}$. Later, after the discovery 9 of inexpensive fossil fuels, our society became dependent on petroleum derivatives. 10 Nowadays, the new concept of biorefinery ${ }^{3}$ has emerged pursuing the integration of the 11 production of fuels (biofuels), heat and electricity (biopower) and platform molecules 12 from biomass. A clear pathway to producing such platform molecules is the catalytic 13 transformation of sugars. For example, Fig. 1 shows a tentative representation of the 14 production of sugars from biorenewable resources and their transformation into some 15 bioproducts of interest.

16 However, biochemical processes are more applicable due to the thermal instability of 17 carbohydrates. Nowadays fermentation processes dominate the production of biofuels 18 and value-added compounds from carbohydrates. Currently, few products are directly 19 obtained from carbohydrates by catalysis such as gluconic acid, sorbitol and 20 hydroxymethylfurfural. ${ }^{4}$

21 Lactic acid is the most widely occurring hydroxycarboxylic acid and has several 22 applications in food industry, chemical sector and polymer market. ${ }^{5,6}$ Even though 23 there is a chemical synthesis route from petrochemical resources (acetaldehyde), ${ }^{7}$ about $2490 \%$ of lactic acid is commercially produced by the microbial fermentation of aqueous 
1 glucose. ${ }^{8}$ However, biological processes in general have various drawbacks including

2 low reaction rates causing long reaction times and the need for huge reactors, and low 3 concentrations of products usually in water solutions requiring high energy

4 consumption for their purification. In addition, biological processes are quite sensitive 5 to $\mathrm{pH}$ and temperature parameters. ${ }^{9}$

6 Homogeneous catalysts have been tested as an alternative to fermentation processes

7 and some compounds have been found to be efficient in the catalytic transformation of 8 sugars, for example $\mathrm{NaOH},{ }^{10} \mathrm{H}_{2} \mathrm{SO}_{4}{ }^{11}$ and $\mathrm{ZnSO}_{4} \cdot{ }^{12}$ However, these reactions are 9 carried out under extreme conditions of temperature and pressure, and the catalysts are 10 toxic or corrosive. Their recovery can therefore be a difficult process.

11 Recent research has focused on heterogeneous catalysis due to the growing industrial 12 interest in processes for the conversion of sugars to value-added products and the 13 drawbacks of the other alternatives. ${ }^{13,14}$ In 2005 , Hayashi et al. ${ }^{15}$ found that Ti-based 14 Lewis acids such as $\mathrm{SnCl}_{4}$ and $\mathrm{SnCl}_{2}$ were efficient catalysts for sugar transformation. 15 A few years later, Taarning et al. ${ }^{16}$ applied Beta zeolite containing Al, Zr, Ti and Sn, 16 achieving interesting results with Sn-Beta zeolite in the conversion of triose 17 dihydroxyacetone to methyl lactate. An interesting research study carried out by Holm 18 et al. ${ }^{17}$ in 2010 reported high conversion of common sugars (such as glucose, fructose 19 and sucrose) catalyzed with Lewis acidic zeotypes for the direct formation of methyl 20 lactate, achieving high selectivity. West et al. ${ }^{18}$ made a study of liquid-phase 21 isomerization of trioses to methyl lactate using commercially available zeolite H-USY 22 as a catalyst, obtaining effective results. In 2011 , Li et al. ${ }^{19}$ used ordered mesoporous 23 substituted silicates with MCM-41 type structure (such as Al-, Ga- and Sn-MCM-41) 24 obtaining high catalytic performance in the complete conversion of trioses to the desired 
1 lactate. In the same year, Wang et al. ${ }^{20}$ demonstrated that tin ion-exchanged 2 montmorillonite, which is a Brønsted acid, shows a high catalytic activity and 3 selectivity for the conversion of trioses into methyl lactate. In recent research,

4 Osmundsen et al. ${ }^{21}$ tested different microporous and mesoporous stannosilicates such 5 as Sn-BEA, Sn-MFI, Sn-MCM-41 and Sn-SBA-15, observing their potential as 6 catalysts for the conversion of trioses and sucrose to methyl lactate with high activity 7 and selectivity. Recent reports have demonstrated that tin-containing compounds ${ }^{21-23}$ 8 exhibit a high catalytic activity in the aqueous isomerization of sugars.

9 In the present work, MCM-41 modified with tin was synthesized. Sn-MCM-41 was 10 tested as catalyst in the transformation of glucose to methyl lactate. Other catalysts such 11 as zeolite ZSM-5 and microporous titanosilicate materials (ETS-10) ${ }^{24}$ and layered 12 materials (JDF-L1 ${ }^{25}$ and AM-4 ${ }^{26,27}$ ) were chosen for the comparison of their catalytic 13 results with those of Sn-MCM-41. Besides, zeolites offer a strong limitation to 14 molecular diffusion, and the accessibility to catalytic sites in layered materials can be 15 drastically enhanced by their exfoliation. ${ }^{28}$ For this reason, UZAR-S1 ${ }^{29}$ and UZAR-S2, $16{ }^{30}$ which are exfoliated materials obtained from JDF-L1 and AM-4, respectively, were 17 also tested.

19 Materials and methods

20 Catalyst preparation

$21 \mathrm{MCM}-41$ with a nominal atomic $\mathrm{Si} / \mathrm{Sn}$ ratio of 75 was prepared by dissolving 1.015 $22 \mathrm{~g}$ hexadecyltrimethyl-ammonium bromide (CTABr) (98\%, Sigma) in $45 \mathrm{~mL}$ of 23 deionized water with $0.417 \mathrm{~g}$ of $\mathrm{NaOH}$ (98\%, pellets (anhydrous), Sigma-Aldrich).

24 Then $0.05 \mathrm{~g}$ of $\mathrm{SnCl}_{2}$ dihydrate (98\%, Sigma-Aldrich) was added to this solution as the 
1 Sn source. Finally, $3.41 \mathrm{~g}$ of tetraethyl orthosilicate (TEOS) (98\%, Aldrich) was also

2 added. The mixture gave rise to a gel with a molar composition of 6 TEOS: 1 CTABr:

$3900 \mathrm{H}_{2} \mathrm{O}: 4 \mathrm{NaOH}: 0.08 \mathrm{SnCl}_{2}$ which was heated under reflux at $80{ }^{\circ} \mathrm{C}$ for $8 \mathrm{~h}$. The solid

4 product was recovered by filtration, washed with deionized water and dried at $70{ }^{\circ} \mathrm{C}$

5 overnight. The dried Sn-MCM-41 was calcined for activation in still air at $650{ }^{\circ} \mathrm{C}$ for 8

6 h. For the purposes of comparison, MCM-41 was synthetized in the same way but

7 without the addition of a tin source.

8 Commercial zeolite ZSM-5 (Zeolyst International, $\mathrm{Si} / \mathrm{Al}=25$ ) and microporous 9 titanosilicate materials (JDF-L1, AM-4, ETS-10, UZAR-S1 and UZAR-S2) were also 10 used. JDF-L1 and AM-4 were synthesized at $230{ }^{\circ} \mathrm{C}$ for $24 \mathrm{~h}$ by a seeded secondary 11 growth procedure using the following molar compositions: $\mathrm{SiO}_{2}: \mathrm{TiO}_{2}: \mathrm{Na}_{2} \mathrm{O}: \mathrm{H}_{2} \mathrm{O}$ 12 4.2:1:2.9:101 and 4.2:1:2.9:68, respectively. To obtain UZAR-S1 and UZAR-S2, the 13 layered materials were protonated in the presence of acetic acid and swollen using 14 nonylamine. For exfoliation, the swollen materials were mixed with an $\mathrm{HCl} / \mathrm{H}_{2} \mathrm{O} / \mathrm{EtOH}$ 15 solution at $55{ }^{\circ} \mathrm{C}$ for $8 \mathrm{~h}$ under reflux. More details of these procedures can be found 16 elsewhere. ${ }^{28,29}$

17 Besides, ETS-10 crystals of about $400 \mathrm{~nm}$ in size were prepared according to 18 previously reported procedures ${ }^{24}$ by hydrothermal synthesis at $230^{\circ} \mathrm{C}$ for $24 \mathrm{~h}$, using $19 \mathrm{TiO}_{2}$-anatase (nanopowder, $<25 \mathrm{~nm}$ particle size, $99.7 \%$, Aldrich) with a gel of molar 20 composition 5.5 $\mathrm{SiO}_{2}: 1 \mathrm{TiO}_{2}$ : $4.6 \mathrm{Na}_{2} \mathrm{O}: 1.9 \mathrm{~K}_{2} \mathrm{O}: 147 \mathrm{H}_{2} \mathrm{O}$.

\section{Catalyst characterization}

Powder low angle X-ray diffraction (LA-XRD) patterns were recorded on a Siemens 
$1 \quad 1-8^{\circ}$ at a step size of $0.01^{\circ}$. Also, some materials were characterized by conventional X-

2 ray diffraction $(\mathrm{XRD})$ using a $\mathrm{D}-\mathrm{Max}$ Rigaku System with a $\mathrm{Cu}-\mathrm{K} \alpha_{1}$ radiation $(\lambda=$ $3 \quad 1.5418 \AA$ ) over a $2 \theta$ range of $2.5-40^{\circ}$.

4 Elemental analysis was performed to determine the $\mathrm{Si} / \mathrm{Sn}$ ratio in $\mathrm{Sn}-\mathrm{MCM}-41$ 5 samples using a Thermo Electron ARL ADVATXP X-ray fluorescence (XRF) 6 sequential spectrometer equipped with an X-ray tube Be window and a Rh anode.

7 Nitrogen adsorption/desorption isotherms were obtained using a Micromeritics

8 Tristar 3000 surface area and porosity analyzer, after previously degassing the samples 9 at $200{ }^{\circ} \mathrm{C}$ for $8 \mathrm{~h}$ under vacuum. The specific surface area was calculated by the BET 10 (Brunauer-Emmett-Teller) method.

11 TEM pictures were taken with a FEI TECNAI T20 transmission electron 12 microscope at $200 \mathrm{kV}$.

13 Thermogravimetric analyses (TGA) were performed in air from room temperature to $14750{ }^{\circ} \mathrm{C}$ with a heating rate of $10{ }^{\circ} \mathrm{C} / \mathrm{min}$ using Mettler Toledo TGA/SDTA $851^{\mathrm{e}}$ 15 equipment.

\section{Catalytic reaction}

18 The conversion of sugars to methyl lactate was performed by dissolving $225 \mathrm{mg}$ of 19 D-(+)-glucose (99\%, Alfa Aesar) in $8.0 \mathrm{~g}$ of methanol (HPLC, Scharlau). $30 \mathrm{mg}$ of 20 naphthalene (99\%, Aldrich) was added as internal standard. The catalyst (160 mg) was 21 dispersed in the methanol solution. The mixture was then sealed in a $35 \mathrm{~mL}$-Teflon-line autoclave and heated to $160^{\circ} \mathrm{C}$ for different times in a rotary oven. products were quantitatively measured by mass detector gas chromatography (GC-MS). 
1 The equipment used was an Agilent 6850 GC system with a capillary column HP-5MS

$2(30 \mathrm{~m} \times 0.250 \mathrm{~mm} \times 0.25 \mu \mathrm{m})$, coupled with an Agilent 5975C MSD.

3 The yields of the different products were determined based on the internal standard

4 of naphthalene using calibration curves made with the commercial compounds methyl-

5 S-(-)-lactate (98\%, Aldrich), methyl glycolate (98\%, Alfa Aesar), methylglyoxal 1,1-

6 dimethylacetal, also called pyruvaldehyde dimethyl acetal (97\%, Aldrich), and 1,1,2,2-

7 tetramethoxypropane (99\%, Aldrich). Unidentified compounds detectable by GC-MS

8 were calculated from the response factor of the methyl lactate. Yields were calculated

9 on a carbon basis. Glucose conversion was determined using an analytical method,

10 which consists of an enzymatic quantitative determination of glucose (Glucose (HK)

11 Assay Kit, Sigma).

12 In the reusability experiments, the recovered catalyst was washed with methanol at 13 room temperature and dried in an oven at $60^{\circ} \mathrm{C}$ overnight prior to reuse.

15 Results and discussion

\section{Catalyst characterization}

$\mathrm{XRF}$ analysis showed that the $\mathrm{Sn}-\mathrm{MCM}-41$ samples had a $\mathrm{Si} / \mathrm{Sn}$ atomic ratio in the range of 50-60 (mean=55; standard deviation=11; samples=3), lower than the nominal ratio $(\mathrm{Si} / \mathrm{Sn}=75)$ and thus indicating a high degree of tin incorporation in the catalysts.

Fig. 2a shows the LA-XRD pattern of MCM-41 and Sn-MCM-41. The highest peak 21 observed for both samples $\left(2.48^{\circ}\right.$ and $2.33^{\circ}$ for MCM-41 and Sn-MCM-41, respectively) 22 indicates the order of the mesopores, as expected in MCM-41 type ordered mesoporous 23 structures. In agreement with previous reports, the Sn-MCM-41 sample shows (100), 24 (110), (200) and (210) reflections, characteristic of hexagonal channel arrays. No 
1 diffraction bands were observed at angles higher than $6^{\circ}$, thus demonstrating the 2 amorphous nature of the samples. The values of the unit cell parameter $\left(\mathrm{a}_{0}=2 \cdot \mathrm{d}_{100} / 3^{0.5}\right)$

3 are 4.11 and $4.38 \mathrm{~nm}$ for MCM-41 and Sn-MCM-41, respectively. These values, within 4 the range reported by other authors for Sn-MCM-41, ${ }^{31,32}$ suggest that tin is incorporated 5 in the framework of the MCM-41. The differences would be due to the larger size of $6 \mathrm{Sn}^{4+}$ (ionic radius $0.55 \AA$ ) compared with that of $\mathrm{Si}^{4+}$ (ionic radius $0.26 \AA$ ) as well as $\mathrm{Sn}$ -

7 O having a longer bond length than that of Si-O. Both effects produce an increase in the 8 unit cell parameter of Sn-MCM-41. The incorporation of tin in tetrahedral coordination 9 within the MCM-41 framework can generate Lewis acidity. ${ }^{19}$

Fig. $2 \mathrm{~b}$ presents the XRD patterns of the other catalysts used in the transformation

11 of glucose. The XRD patterns of ETS-10, JDF-L1, AM-4 and ZSM-5 show high angle 12 diffraction lines which indicate that the materials are crystalline. UZAR-S1 and UZAR$13 \mathrm{~S} 2$, as for other delaminated porous materials, are XRD-amorphous exhibiting broad 14 reflections of the parent materials JDF-L1 and AM-4, respectively. ${ }^{28,29}$

15 Calcination was used to remove the organic surfactant from as-synthesized SnMCM-41. The TGA curve (not shown) revealed that the weight loss of as-synthetized

17 Sn-MCM-41 is around $40 \%$, corresponding to the surfactant. However, the activated Sn-MCM-41 curve did not show this weight loss, showing that the calcination process was done properly.

The TEM images in Figs. 3a and 3b correspond to as-synthesiszed Sn-MCM-41.

21 The homogeneity of these images suggests a good dispersion of tin atoms in the MCM-

2241 structure. The TEM images of activated Sn-MCM-41 reveal the presence of pores 23 (Figs. 3c and 3d) where no morphological changes are observed with respect to the as24 synthesized sample. 
1 The BET surface area for Sn-MCM-41 is $801 \mathrm{~m}^{2} / \mathrm{g}$ (Table 1), which is very close to 2 that of MCM-41 synthesized in the same way. The Sn-MCM-41 pore volume is lower 3 than that of MCM-41; this could be owing to tin atoms inserted into the structure. ZSM45 and ETS-10 give BET surface areas of 367 and $253 \mathrm{~m}^{2} / \mathrm{g}$, typical values for these 5 microporous materials. JDF-L1 and AM-4 scarcely adsorb $\mathrm{N}_{2}$ and this is reflected by 6 BET specific surface areas of 30 and $13 \mathrm{~m}^{2} / \mathrm{g}$, respectively. The exfoliation process 7 increases the BET surface area with respect to the as-synthesized materials, attaining 8 BET specific surface areas of 159 and $112 \mathrm{~m}^{2} / \mathrm{g}$ for UZAR-S1 and UZAR-S2, 9 respectively.

\section{Catalytic results}

12 Different catalysts were used in the transformation of glucose in methanol to obtain 13 methyl lactate (ML) as the desired product. However, other side-products were detected 14 by GC-MS. In this work only three of these side-products were quantified: methyl 15 glycolate (MG), pyruvaldehyde dimethyl acetal (PADA) and 1,1,2,216 tetramethoxypropane (TMP). Based on previous reports $16,17,20$ and the different 17 products identified by GC-MS, a possible reaction pathway has been developed (Fig. 4).

18 In an alcohol medium (methanol), hexoses such as glucose suffer retro-aldol reactions 19 to form carbohydrate products with lower numbers of carbon atoms. On the one hand, a 20 compound with four carbon atoms such as erythroxe is formed, which undergoes 21 different transformations until obtaining methyl glycolate (MG) as the final product. On 22 the other hand, compounds with three carbon atoms are formed such as glyceraldehyde 23 and dihydroxyacetone which are lactic acid isomers. These products lose water 24 molecules and form pyruvaldehyde, which in methanol suffers a reversible reaction to 
1 obtain pyruvaldehyde dimethyl acetal (PADA) and another reaction to form methyl 2 lactate (ML), our desired product. However, PADA could undergo changes to form 3 1,1,2,2-tetramethoxypropane (TMP), another reaction product.

4 In this work, different solid catalysts have been used in the transformation of 5 glucose to methyl lactate. The yields of the quantified products are presented in Table 2. 6 Sn-MCM-41 provides the highest methyl lactate and total yields of $43 \%$ and $59 \%$, 7 respectively, demonstrating that $\mathrm{Sn}-\mathrm{MCM}-41$ has a pore system sufficiently large for 8 glucose to enter. Conventional MCM-41 is considerably less active for the reaction than 9 Sn-MCM-41, which is encouraging. Additionally, it should be noted that for Sn-MCM1041 , the catalytic experiments were repeated 4 times in the same conditions with an 11 average methyl lactate yield value of $42.7 \%$ and standard deviation of $5.1 \%$, 12 highlighting the reproducibility of the results. Similar to the case of zeolites, the 13 catalytic behavior is related to the Lewis acidity ascribed to $\mathrm{Sn}$ incorporated in the 14 MCM-41. ${ }^{17}$ The Lewis acid sites can favor the retro-aldol reactions with the cleavage 15 of C-C bonds of glucose (Fig. 4) to form trioses. ${ }^{33}$ Moreover, it has been demonstrated 16 that Sn-MCM-41 could have the combination of acid sites leading to the conversion of 17 trioses to lactates. ${ }^{19}$ Other reaction pathways are possible such as polymerization that 18 products have not been analyzed. This can explain the lower total yield in comparison to 19 the conversion of glucose.

20 The methyl lactate yield obtained with Sn-MCM-41 is comparable to that obtained 21 in similar operating conditions $\left(160^{\circ} \mathrm{C}\right.$ and $\left.20 \mathrm{~h}\right)$ by Holm et al. ${ }^{17}$ using Sn-Beta zeolite 22 as catalyst (methyl lactate yield, $43 \%$ ) and higher than the yields obtained by the same 23 authors using other metal containing zeolites: Ti-Beta (methyl lactate yield, $31 \%$ ) and 24 Zr-Beta (methyl lactate yield, $33 \%$ ). In the conversion of sucrose (disaccharide 
1 composed of glucose and fructose) at $160{ }^{\circ} \mathrm{C}$ for $16 \mathrm{~h}$, Osmundsen et al. ${ }^{21}$ achieved a 2 methyl lactate yield of $25 \%$ using Sn-MCM-41. Using Sn-Beta zeolite with $\mathrm{Si} / \mathrm{Sn}=200$, 3 these authors achieved a methyl lactate yield close to $60 \%$. Also using Sn-MCM-41, Li 4 et al. ${ }^{19}$ converted trioses (dihydroxiacetone) in ethanol to ethyl lactate with a yield of 98 $5 \%$ after $6 \mathrm{~h}$ at a lower temperature $\left(90^{\circ} \mathrm{C}\right)$ than the temperature used here. It has been 6 pointed out ${ }^{21}$ that the use of hexose sugars is significantly more interesting, due to their 7 lower cost compared to trioses, but more challenging, due the possibility of other 8 reaction pathways occurring that may decrease the yield to lactate compounds. Finally, 9 Sn-MCM-41 has been used as catalyst in the isomerization of glucose into fructose and 10 mannose. Moliner et. al. ${ }^{22}$ obtained about $30 \%$ of glucose conversion with $40 \%$ 11 fructose selectivity at $140{ }^{\circ} \mathrm{C}$ and $90 \mathrm{~min}$ of reaction in an aqueous medium. These 12 operating conditions are different from those used here (methanol, $160^{\circ} \mathrm{C}$ and optimum 13 time $20 \mathrm{~h}$ ), but it cannot be ruled out that these reactions could occur. In fact, 14 Osmundsen et al. ${ }^{21}$ found a fructose yield of about $80 \%$ at much lower temperatures $15\left(80^{\circ} \mathrm{C}\right)$ for $48 \mathrm{~h}$ in methanol.

16 For the layered materials (JDF-L1 and AM-4) and for microporous titanosilicate 17 ETS-10 and zeolite ZSM-5, the methyl lactate yields are very low, under 4\%. The 18 exfoliated materials UZAR-S1 and UZAR-S2 give higher yields to the total products 19 and to methyl lactate than their respective layered precursors. This behavior is in 20 agreement with the observed role of delayered zeolitic materials (ITQ-2, ITQ-6 and 21 ITQ-18), with good access of the reactants to their catalytic sites as well as fast 22 desorption of the products, for example in the synthesis of bulky diamino diphenyl 23 methane. ${ }^{34}$ It should be noted that UZAR-S2, which is protonated, gave the highest 24 yields to PADA, indicating that the conversion of pyruvaldehyde to PADA was favored 
1 with Brønsted acidic catalysts against the parallel route to methyl lactate (see scheme in 2 Fig. 4).

3 The evolution with time of the catalytic performance of Sn-MCM-41 was also 4 studied (Fig. 5). At short times, the yield of methyl lactate increased with time. 5 However, at long times the yield reached a constant value of around $43 \%$; therefore, 20

$6 \mathrm{~h}$ is considered as the optimum time. The rest of the products gave lower yields, below $7 \quad 10 \%$. The PADA yield decreased with time because it reacted to give TMP. Also, at 8 high conversion it could be converted into methyl lactate with the back reaction shown 9 in Fig. 4 (18). TMP produced from PADA appeared when the PADA diminished. As 10 expected for a final product, there was an increase in the MG yield with time to reach an 11 optimum at $20 \mathrm{~h}$.

12 Sn-MCM-41 was tested in three consecutive catalytic cycles to evaluate its 13 reusability (Fig. 6). The methyl lactate yield was slightly reduced, the first, second and 14 third cycles giving methyl lactate yields of $43 \%, 41 \%$ and $39 \%$, respectively. This 15 lower activity could be explained by the reduction in the accessibility of active centers 16 due to the adsorption of reaction products or structural changes. In any event, the use of 17 methanol instead of water as solvent avoids coke deposition and structural damage, as 18 has been shown in the conversion of trioses in H-USY zeolite. The yield to MG (Fig. 6) 19 has low values and decreased in consecutive cycles from $3.4 \%$ to $2.0 \%$. The PADA 20 yields vary from $4.6 \%$ in the first cycle to $7.5 \%$ in the second and $6.4 \%$ in third. This 21 indicates that some properties of the catalysts could change to favor the production of 22 PADA instead of methyl lactate. Finally, the yield to TMP in the three cycles is 23 insignificant, being around $1.5 \%$ in all cases. 
1 It is well known that MCM-41 type catalysts have limited hydrothermal stability, so

2 the catalyst was characterized after its use in glucose conversion. The BET surface area

3 and pore volume decreased after use (Table 1), consistent with the slight activity

4 decrease. The TEM of the used catalysts (Fig. 3e) shows the pore structure of MCM-41

5 with no appreciable changes in the morphology.

6 The thermal behavior of the catalyst was also studied (not shown). TGA of the as-

7 synthetized Sn-MCM-41 indicates that the CTABr surfactant was completely removed,

8 as indicated above. The solid after reaction has a total weight loss of around $13 \%$. A

9 first weight loss below $100^{\circ} \mathrm{C}$ (around $2 \%$ ) is due to the adsorbed methanol. After 100

$10{ }^{\circ} \mathrm{C}$, there are several weight losses up to $600{ }^{\circ} \mathrm{C}$ which could be related to absorbed

11 compounds and, at the highest temperatures, to carbonaceous species that would be 12 responsible for catalyst deactivation.

13 In their reusability study, Holm et al. (17) regenerated the catalysts (Sn, Ti, Zr- Beta

14 zeolites) by calcination after each cycle. The catalysts were stable but in a fixed bed

15 reactor the Sn-Beta zeolite deactivated gradually with time. There is a similarity

16 between the fixed bed reactor and our operating conditions, where the catalyst is only

17 washed with methanol and not regenerated by calcination after each cycle to remove the

18 carbonaceous deposits observed by TGA. In fact, for a Sn-MCM-41 catalyst,

19 Osmundsen et al. ${ }^{21}$ and Li et al., ${ }^{19}$ using sucrose and trioses as reactants, respectively,

20 found that the deposition of carbon species deactivated the catalysts and that washing

21 with solvent was not enough to regenerate them. 


\section{Conclusions}

2 Sn-MCM-41 material with an atomic ratio $\mathrm{Si} / \mathrm{Sn}=55$ showed good results in the 3 conversion of glucose to methyl lactate with yields of around $43 \%$. Regarding its 4 stability, similar yields to methyl lactate were obtained in three consecutive reaction 5 cycles with only a slight reduction that can be explained by the surface area reduction 6 and/or carbonaceous deposits. Other microporous materials tested exhibited lower

7 yields to methyl lactate. Exfoliated materials (UZAR-S1 and UZAR-S2) allowed better

8 accessibility of glucose to the catalytic sites and fast desorption of the products, 9 increasing the reaction yield in comparison with their corresponding precursor layered 10 materials (JDF-L1 and AM-4).

\section{Acknowledgements}

13 The authors gratefully acknowledge the Spanish Ministry of Economy and 14 Competitiveness (MINECO) for financial support through project MAT2010-15870, as 15 well as the Regional Government of Aragón (DGA), the Obra Social La Caixa (GA-LC16 019/2011) and the European Social Fund (ESF). C. Casado also thanks MINECO for 17 the "Ramon y Cajal" program (RYC-2011-08550). Authors also would like to 18 acknowledge the use of Servicio General de Apoyo a la Investigación-SAI, Universidad 19 de Zaragoza. 


\section{$1 \quad$ References}

2 1. Bulushev DA and Ross JRH, Catalysis for conversion of biomass to fuels via 3 pyrolysis and gasification: A review. Catal Today 171:1-13 (2011). DOI: $4 \quad 10.1016 /$ j.cattod.2011.02.005.

5 2. Ragauskas AJ, Williams CK, Davison BH, Britovsek G, Cairney J, Eckert CA, 6 Frederick WJ, Hallett JP, Leak DJ, Liotta CL, Mielenz JR, Murphy R, Templer R, 7 Tschaplinski T, The Path Forward for Biofuels and Biomaterials. Science 311:484-489 8 (2006). DOI: 10.1126/science.1114736.

9 3. Huber GW and Dumesic JA, An overview of aqueous-phase catalytic processes for 10 production of hydrogen and alkanes in a biorefinery. Catal. Today 111:119-132 (2006). 11 DOI: 10.1016/j.cattod.2005.10.010.

12 4. Zhao H, Holladay JE, Brown $\mathrm{H}$, Zhang ZC, Metal chlorides in ionic liquid solvents 13 convert sugars to 5-hydroxymethylfurfural. Science 316:1597-1600 (2007). DOI: $14 \quad 10.1126 /$ science.1141199.

15 5. Datta $R$ and Henry $M$, Lactic acid: recent advances in products, processes and 16 technologies - a review. J Chem Technol Biotechnol 81:1119-1129 (2006). DOI: $17 \quad 10.1002 /$ jctb. 1486.

18 6. Kong L, Li G, Wang H, He W and Ling F, Hydrothermal catalytic conversion of 19 biomass for lactic acid production. J Chem Technol Biotechnol 83:383-388 (2008). 20 DOI: $10.1002 /$ jctb. 1797.

21 7. Wee Y, Kim J and Ryu H, Biotechnological production of lactic acid and its recent 22 applications. Food Technol Biotechnol 44:163-172 (2006).

23 8. Joglekar HG, Rahman I, Babu S, Kulkarni BD and Joshi A, Comparative assessment 24 of downstream processing options for lactic acid. Sep Purif Technol 52:1-17 (2006). 25 DOI: 10.1016/j.seppur.2006.03.015. 
1 9. Lima S, Dias AS, Lin Z, Brandão P, Ferreira P, Pillinger M, Rocha J, Calvino-

2 Casilda $\mathrm{V}$ and Valente $\mathrm{AA}$, Isomerization of d-glucose to d-fructose over metallosilicate

3 solid bases. App Catal A 39:21-27 (2008). DOI: 10.1016/j.apcata.2007.12.030.

4 10. Kishida H, Jin F, Yan X, Moriya T and Enomoto H, Formation of lactic acid from

5 glycolaldehyde by alkaline hydrothermal reaction. Carbohydr Res 341:2619-2623

6 (2006). DOI: 10.1016/j.carres.2006.06.013.

7 11. Antal Jr. MJ, Mok WSL and Richards GN, Four-carbon model compounds for the 8 reactions of sugars in water at high temperature. Carbohydr Res 199:111-115 (1990).

9 DOI: 10.1016/0008-6215(90)84097-E.

12. Bicker M, Endres S, Ott L and Vogel H, Catalytical conversion of carbohydrates in subcritical water: A new chemical process for lactic acid production. J Mol Catal A: Chem 239:151-157 (2005). DOI: 10.1016/j.molcata.2005.06.017.

13. Perego $\mathrm{C}$ and Bosetti A, Biomass to fuels: The role of zeolite and mesoporous materials. Microporous Mesoporous Mater

144:38-39 (2011). DOI: 15 10.1016/j.micromeso.2010.11.034. 14. Liu Z, Li W, Pan C, Chen P, Lou H and Zheng X, Conversion of biomass-derived carbohydrates to methyl lactate using solid base catalysts. Catal Commun 15:82-87 (2011). DOI: 10.1016/j.catcom.2011.08.019.

15. Hayashi Y and Sasaki Y, Tin-catalyzed conversion of trioses to alkyl lactates in alcohol solution. Chem Commun 2716-2718 (2005). DOI: 10.1039/B501964H.

21 16. Taarning E, Saravanamurugan S, Spangsberg Holm M, Xiong J, West R and 22 Christensen $\mathrm{CH}$, Zeolite-catalyzed isomerization of triose sugars. ChemSusChem 2:625627 (2009). DOI: 10.1002/cssc.200900099. 
1 18. West RM, Holm MS, Saravanamurugan S, Xiong J, Beversdorf Z, Taarning E and

2 Christensen $\mathrm{CH}$, Zeolite H-USY for the production of lactic acid and methyl lactate

3 from C3-sugars. J Catal 269:122-130 (2010). DOI: 10.1016/j.jcat.2009.10.023.

4 19. Li L, Stroobants C, Lin K, Jacobs PA, Sels BF and Pescarmona PP, Selective

5 conversion of trioses to lactates over Lewis acid heterogeneous catalysts. Green Chem

6 13:1175-1181 (2011). DOI: 10.1039/C0GC00923G.

7 20. Wang J, Masui Y and Onaka M, Conversion of triose sugars with alcohols to alkyl

8 lactates catalyzed by Brønsted acid tin ion-exchanged montmorillonite. App Catal B

9 107:135-139 (2011). DOI: 10.1016/j.apcatb.2011.07.006.

10 21. Osmundsen CM, Holm MS, Dahl S and Taarning E, Tin-containing silicates:

11 structure-activity relations. Proc $R$ Soc $A$ 468:2000-2016 (2012). DOI:

12 10.1098/rspa.2012.0047..

13 22. Moliner M, Román-Leshkov Y and Davis ME, Tin-containing zeolites are highly 14 active catalysts for the isomerization of glucose in water. Proc Nat Acad Sci 107:6164156168 (2010). DOI: 10.1073/pnas. 1002358107.

16 23. Lew $\mathrm{CM}$, Rajabbeigi $\mathrm{N}$ and Tsapatsis $\mathrm{M}$, Tin-containing zeolite for the 17 isomerization of cellulosic sugars. Microporous Mesoporous Mater 153:55-58 (2012). 18 DOI: 10.1016/j.micromeso.2011.12.020.

19 24. Casado C, Amghouz Z, García JR, Boulahya K, González-Calbet JM, Téllez C and 20 Coronas J, Synthesis and characterization of microporous titanosilicate ETS-10 21 obtained with different Ti sources. Mater Res Bull 44:1225-1231 (2009). DOI: 22 10.1016/j.materresbull.2009.01.015.

23 25. Rubio C, Casado C, Uriel S, Téllez C and Coronas J, Seeded synthesis of layered 24 titanosilicate JDF-L1. Mater Lett 63:113-115 (2009). DOI: $25 \quad$ 10.1016/j.matlet.2008.09.022.

26 26. Lin Z, Rocha J, Brandao P, Ferreira A, Esculcas A, deJesus J, Philippou A and 27 Anderson M, Synthesis and structural characterization of microporous umbite, 
1 penkvilksite, and other titanosilicates. J Phys Chem B 101:7114-7120 (1997). DOI:

$2 \quad 10.1021 / j p 971137 n$.

3 27. Dadachov MS, Rocha J, Ferreira A, Lin Z and Anderson MW, Ab initio structure

4 determination of layered sodium titanium silicate containing edge-sharing titanate

5 chains (AM-4) $\mathrm{Na}_{3}(\mathrm{Na}, \mathrm{H}) \mathrm{Ti}_{2} \mathrm{O}_{2}\left[\mathrm{Si}_{2} \mathrm{O}_{6}\right] \cdot 2.2 \mathrm{H}_{2} \mathrm{O}$. Chem Commun 2371-2372. DOI:

$6 \quad 10.1039 / \mathrm{A} 707106 \mathrm{~J}$

7 28. Corma A, Fornes V, Pergher SB, Maesen TLM and Buglass JG, Delaminated 8 zeolite precursors as selective acidic catalysts. Nature 396:353-356 (1998) 9 DOI:10.1038/24592.

29. Rubio C, Casado C, Gorgojo P, Etayo F, Uriel S, Téllez C and Coronas J, Exfoliated 11 titanosilicate material UZAR-S1 obtained from JDF-L1. Eur J Inorg Chem 159-163 12 (2010). DOI: 10.1002/ejic.200900915.

13 30. Casado C, Ambroj D, Mayoral Á, Vispe E, Téllez C and Coronas J, Synthesis, 14 swelling, and exfoliation of microporous lamellar titanosilicate AM-4. Eur J Inorg 15 Chem 2247-2253 (2011). DOI: 10.1002/ejic.201100152.

16 31. Chaudhari K, Das TK, Rajmohanan PR, Lazar K, Sivasanker S and Chandwadkar 17 AJ, Synthesis, characterization, and catalytic properties of mesoporous tin-containing 18 analogs of MCM-41. J Catal 183: 281-291 (1999). DOI: 10.1006/jcat.1999.2394.

19 32. Gaydhankar TR, Joshi PN, Kalita P and Kumar R, Optimal synthesis parameters and 20 application of Sn-MCM-41 as an efficient heterogeneous catalyst in solvent-free 21 Mukaiyama-type aldol condensation. J Mol Catal A: Chem 265:306-315 (2007). DOI: 22 10.1016/j.molcata.2006.10.041.

23 33. Roman-Leshkov $\mathrm{Y}$ and Davis ME, Activation of carbonyl-containing molecules 24 with solid lewis acids in aqueous media. ACS Catal 1:1566-1580 (2011). DOI: $2510.1021 / \operatorname{cs} 200411 \mathrm{~d}$.

26 34. Botella P, Corma A, Carr RH and Mitchell CJ, Towards an industrial synthesis of 27 diamino diphenyl methane (DADPM) using novel delaminated materials: A 
1

2

3

4

5

6

7

8

9

10

11

12

13

14

15

16

17

18

19

20

21

22

23

24

25

26

27

28

29

30

31

32

33

34

35

36

37

38

39

40

41

42

43

44

45

46

47

48

49

50

51

52

53

54

55

56

57

58

59

60

1 breakthrough step in the production of isocyanates for polyurethanes. App Catal A

2 398:143-149 (2011). DOI: 10.1016/j.apcata.2011.03.026.

3 
1 FIGURE CAPTIONS

2 Fig. 1 Sugars: from biorenewable resources to platform molecules.

3 Fig. 2 a) LA-XRD diffractograms of as-synthesized Sn-MCM-41 and MCM-41. b) XRD

4 diffractograms of microporous catalysts.

5 Fig. 3 TEM images of: a) and b) as-synthesized Sn-MCM-41; c) and d) Sn-MCM-41

6 activated by calcination at $650^{\circ} \mathrm{C}$ in still air; e) Sn-MCM-41 catalyst after $20 \mathrm{~h}$ of reaction.

7 Fig. 4 Possible reaction pathway for the transformation of glucose using Sn-MCM-41 as 8 catalyst.

9 Fig. 5 Product yields as a function of reaction time for the conversion of glucose at $160{ }^{\circ} \mathrm{C}$

10 with Sn-MCM-41. The data at $20 \mathrm{~h}$ correspond to the average values with standard deviations.

11 Acronyms are the same as in Table 2.

12 Fig. 6 Product yields as a function of reuse cycle of Sn-MCM-41 catalyst at $160{ }^{\circ} \mathrm{C}$ during 20

13 h. Acronyms are the same as in Table 2. 


\section{TABLES}

Table 1 BET specific surface area and pore volume measured at $\mathrm{p} / \mathrm{p}_{0}=0.97$ by nitrogen adsorption of the catalysts used in this work.

\begin{tabular}{lcc}
\hline Catalyst & $\begin{array}{r}\text { Surface area } \\
\left(\mathrm{m}^{2} / \mathrm{g}\right)\end{array}$ & $\begin{array}{c}\text { Pore volume } \\
\left(\mathrm{cm}^{3} / \mathrm{g}\right)\end{array}$ \\
\hline$M C M-41$ & 1199 & 0.80 \\
Sn-MCM-41 & 801 & 0.44 \\
JDF-L1 & 30 & 0.08 \\
UZAR-S1 & 159 & 0.17 \\
AM-4 & 13 & 0.05 \\
UZAR-S2 & 112 & 0.18 \\
ZSM-5 & 367 & 0.55 \\
ETS-10 & 253 & 0.14 \\
Used Sn-MCM-41 & & \\
(after 20 h of reaction) & 710 & 0.34 \\
Used Sn-MCM-41 & & \\
(after $3^{\text {rd }}$ reaction cycle) & 689 & 0.31 \\
\hline
\end{tabular}


Table 2. Catalytic results after $20 \mathrm{~h}$ at $160^{\circ} \mathrm{C}(M G$ : methyl glycolate; $M L$ : methyl lactate;

PADA: pyruvaldehyde dimethyl acetal; TMP: 1,1,2,2-tetramethoxypropane).

\begin{tabular}{|c|c|c|c|c|c|c|c|}
\hline \multirow[b]{2}{*}{ Catalyst } & \multicolumn{5}{|c|}{ Analyzed yields (\%) } & \multirow[b]{2}{*}{$\begin{array}{l}\text { Total } \\
\text { yield }\end{array}$} & \multirow{2}{*}{$\begin{array}{c}\text { Glucose } \\
\text { conversion } \\
(\%)\end{array}$} \\
\hline & MG & ML & PADA & TMP & $\begin{array}{c}\text { Un- } \\
\text { indentified } \\
\text { products }\end{array}$ & & \\
\hline Sn-MCM-41 ${ }^{(1)}$ & $3.4 \pm 0.1$ & $42.7 \pm 5.1$ & $4.6 \pm 1.2$ & $1.8 \pm 0.8$ & $6.5 \pm 2.6$ & 59.0 & 100 \\
\hline MCM-41 & 0.7 & 0.7 & 2.8 & 0.1 & 5.1 & 9.4 & 68 \\
\hline JDF-L1 & 3.9 & 1.8 & 1.2 & 0.2 & 1.7 & 8.8 & 85 \\
\hline UZAR-S1 & 2.1 & 3.9 & 4.4 & 0.1 & 6.6 & 17.1 & 93 \\
\hline AM-4 & 2.5 & 1.2 & 0.6 & 0.1 & 0.7 & 5.1 & 72 \\
\hline UZAR-S2 & 3.6 & 5.2 & 19.1 & 0.2 & 12.1 & 40.2 & 79 \\
\hline ETS-10 & 4.8 & 1.9 & 1.5 & 0.2 & 1.4 & 9.8 & 85 \\
\hline ZSM-5 & 1.1 & 3.5 & 0.5 & 0.2 & 9.4 & 14.7 & 89 \\
\hline
\end{tabular}

(1) The average values and standard deviation correspond to four experiments. 


\section{FIGURE 1}

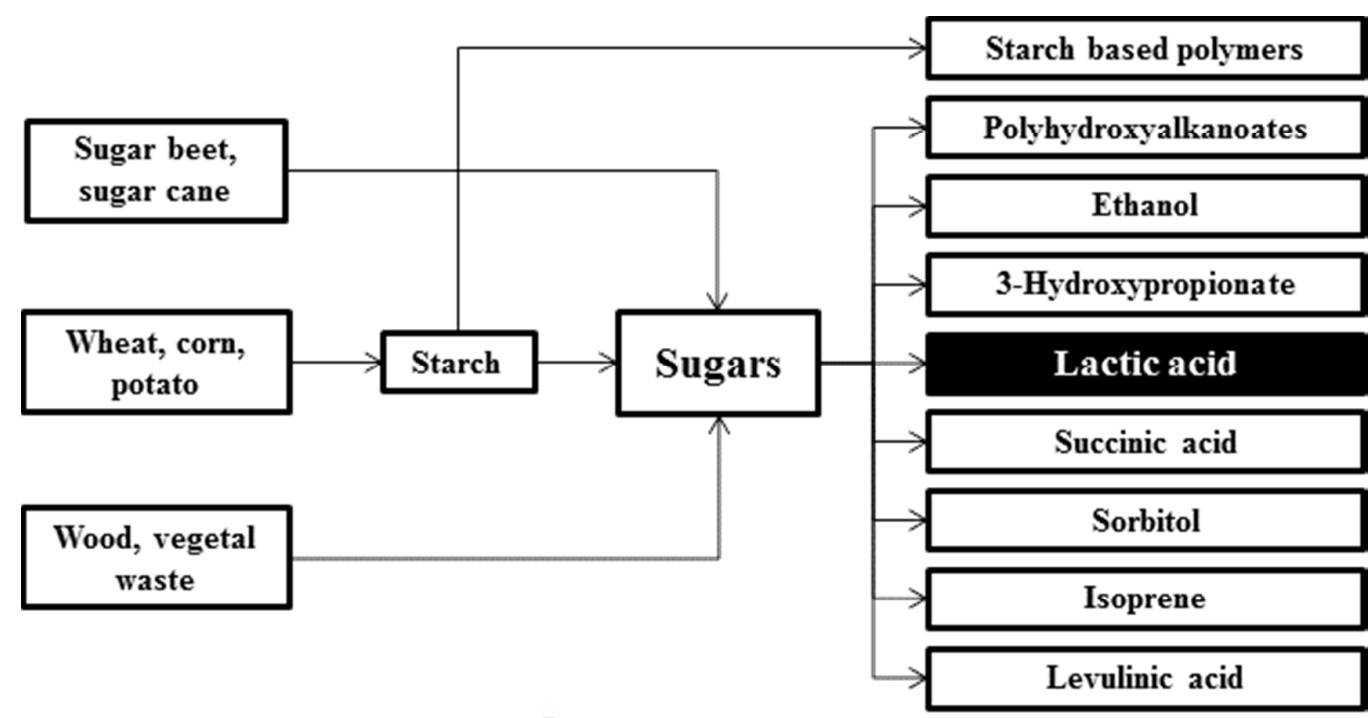




\section{FIGURE 2}
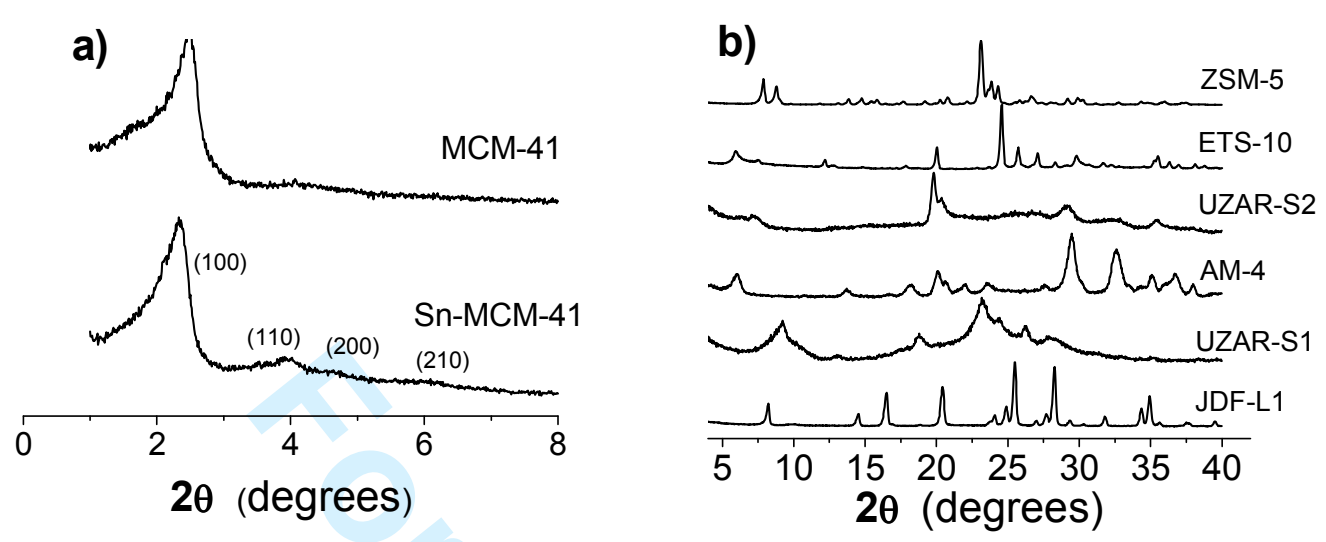

2

22

23

24

25

26

27

28

29

30

31

32

33

34

35

36

37

38

39

40

41

42

43

44

45

46

47

48

49

50

51

52

53

54

55

56

57

58

59

60 
FIGURE 3
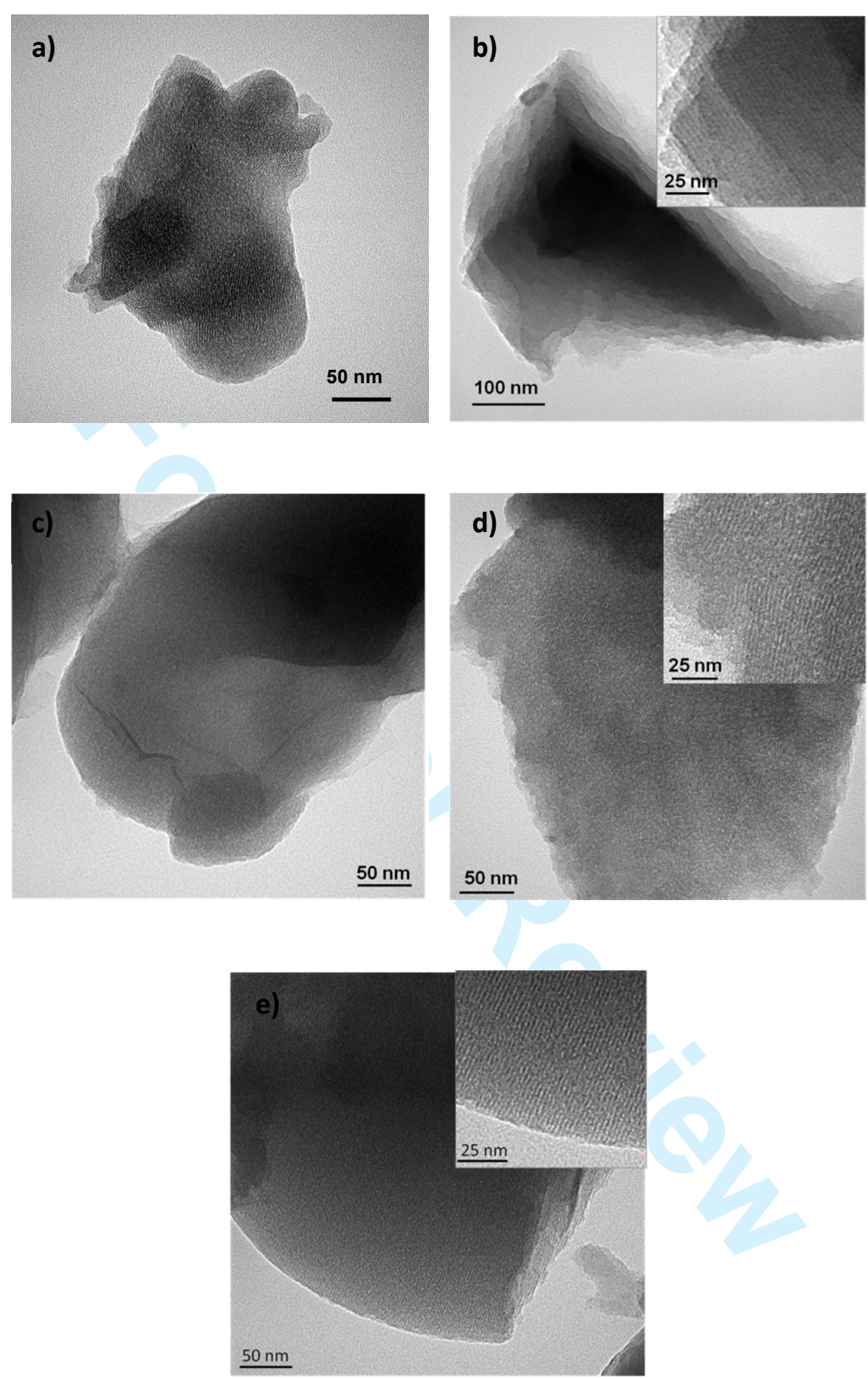
FIGURE 4

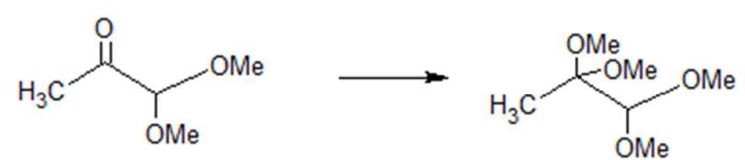

pyruvaldehyde dimethyl acetal (PADA) 1,1,2,2-tetramethoxy propane (TMP)

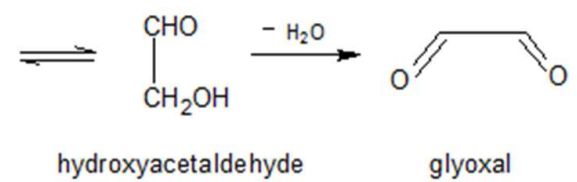

D-erythrose

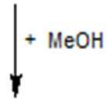<smiles>COC(=O)CO</smiles>
methyl glycolate (MG)

glyceraldehyde dihydroxyacetone

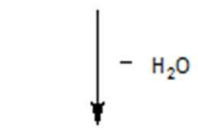

pyruvaldehyde<smiles>C=CC(C)=O</smiles>

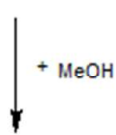<smiles>COC(=O)C(C)O</smiles>

methyl lactate

(ML) 
FIGURE 5

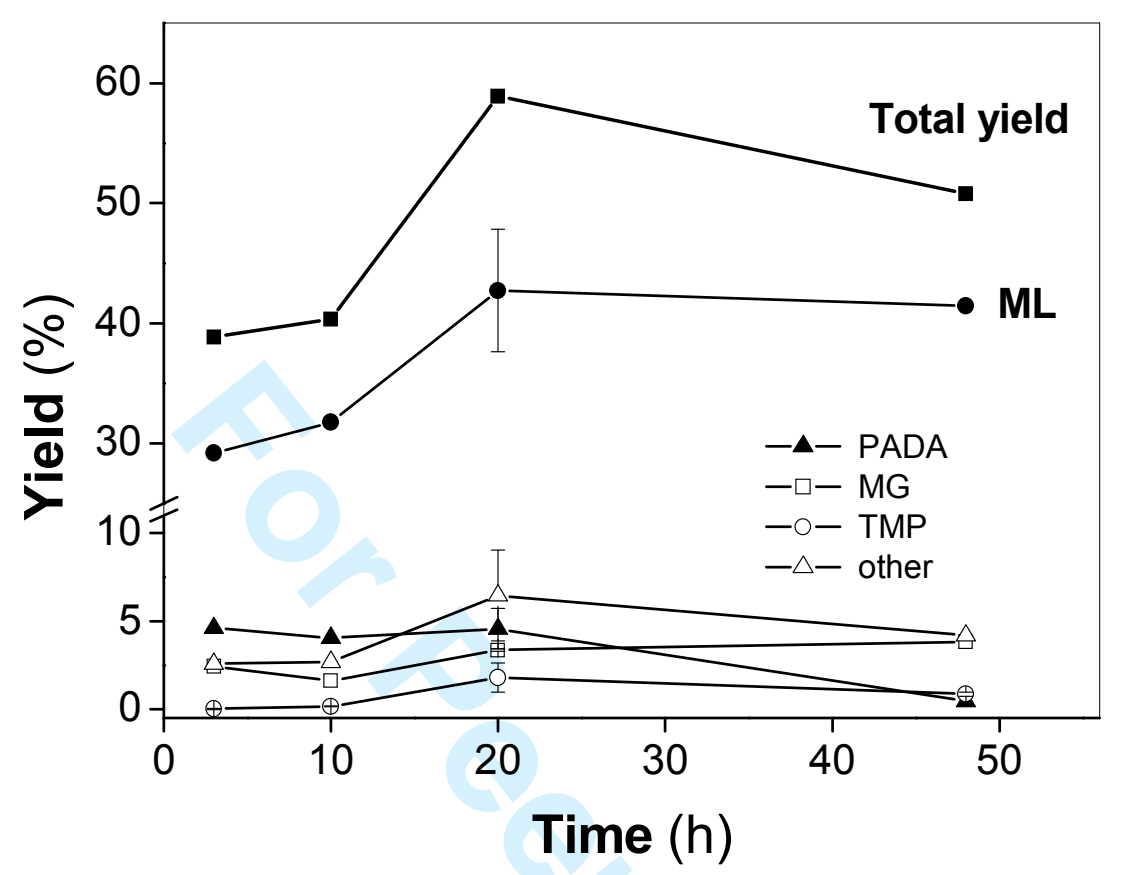




\section{FIGURE 6}

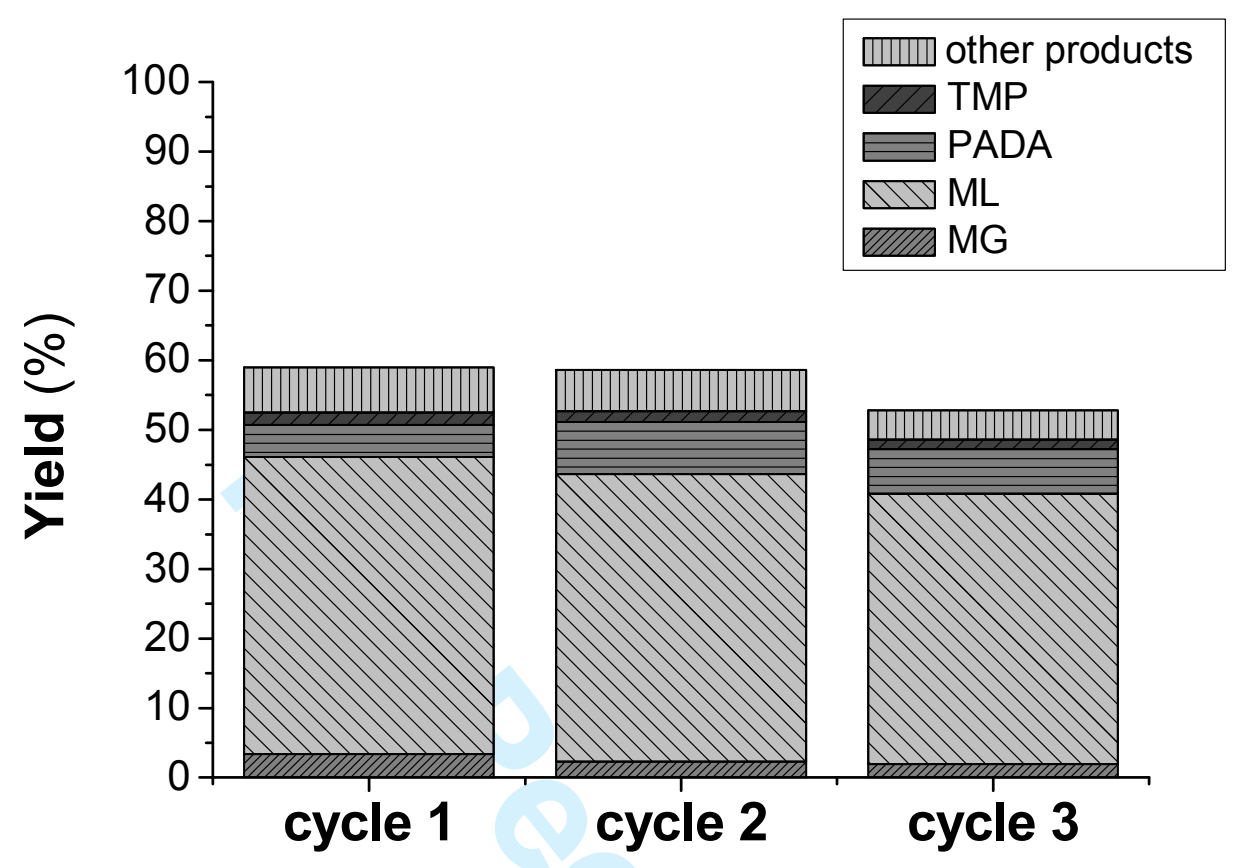

